\title{
Incidence of and risk factors for metachronous gastric cancer after endoscopic resection and successful Helicobacter pylori eradication: results of a large-scale, multicenter cohort study in Japan
}

\author{
Genki Mori $^{1}$ - Takeshi Nakajima ${ }^{1} \cdot K$ Kiyoshi Asada ${ }^{2}$ Taichi Shimazu ${ }^{3}$. \\ Nobutake Yamamichi ${ }^{4}$. Takao Maekita ${ }^{5}$ Chizu Yokoi ${ }^{6} \cdot$ Mitsuhiro Fujishiro $^{4}$. \\ Takuji Gotoda $^{7} \cdot$ Masao Ichinose $^{5} \cdot$ Toshikazu Ushijima $^{2} \cdot$ Ichiro Oda $^{1}$
}

Received: 28 May 2015/Accepted: 7 September 2015/Published online: 29 September 2015

(C) The International Gastric Cancer Association and The Japanese Gastric Cancer Association 2015

\begin{abstract}
Background A previous multicenter prospective randomized study from Japan showed that Helicobacter pylori eradication reduced the development of metachronous gastric cancer (MGC) after endoscopic resection for early gastric cancer. MGC risk, however, is not eliminated; yet few studies have evaluated its long-term incidence and risk factors. In this study, we investigated the incidence of and risk factors for MGC in patients who underwent endoscopic resection for early gastric cancer with successful $H$. pylori eradication.

Methods A total of 594 patients who underwent endoscopic resection for early gastric cancer and successful $H$. pylori eradication at three institutions (National Cancer Center Hospital, University of Tokyo Hospital, and Wakayama Medical University Hospital) were analyzed retrospectively. Annual endoscopic surveillance was
\end{abstract}

Takeshi Nakajima

tnakajim@ncc.go.jp

1 Endoscopy Division, National Cancer Center Hospital, 5-1-1 Tsukiji, Chuo-ku, Tokyo 104-0045, Japan

2 Division of Epigenomics, National Cancer Center Research Institute, Tokyo, Japan

3 Epidemiology and Prevention Group, Research Center for Cancer Prevention and Screening, National Cancer Center, Tokyo, Japan

4 Department of Gastroenterology, University of Tokyo, Tokyo, Japan

5 Second Department of Internal Medicine, Wakayama Medical University, Wakayama, Japan

6 Department of Gastroenterology and Hepatology, National Center for Global Health and Medicine, Tokyo, Japan

7 Department of Gastroenterology and Hepatology, Tokyo Medical University, Tokyo, Japan performed after initial endoscopic resection. MGC was defined as a gastric cancer newly detected at least 1 year after successful $H$. pylori eradication.

Results Ninety-four MGCs were detected in 79 patients during the 4.5-year median follow-up period. KaplanMeier analysis showed the cumulative incidence of MGC 5 years after successful $H$. pylori eradication was $15.0 \%$; the incidence of MGC calculated by use of the person-year method was 29.9 cases per 1000 person-years. Multivariate analysis using the Cox proportional hazards model revealed that male sex, severe gastric mucosal atrophy, and multiple gastric cancers before successful $H$. pylori eradication were independent risk factors for MGC. Eleven percent of MGCs (10 of 94) were detected more than 5 years after successful $H$. pylori eradication.

Conclusion Surveillance endoscopy for MGC in patients who have undergone endoscopic resection for early gastric cancer should be performed even after successful $H$. pylori eradication.

Keywords Gastric cancer - Helicobacter pylori . Multivariate analysis $\cdot$ Incidence $\cdot$ Risk factors

\section{Introduction}

1Endoscopic resection, including endoscopic submucosal dissection (ESD), is currently accepted widely as an effective, minimally invasive local treatment for early gastric cancer with a negligible risk of lymph node metastasis, delivering a favorable long-term outcome [1-7]. However, the development of metachronous gastric cancer (MGC), owing to the preservation of the entire stomach after endoscopic resection, remains a possibility [8-10]. A previous multicenter prospective randomized study performed in Japan showed 
that eradication of Helicobacter pylori reduced the incidence of MGC after endoscopic resection for early gastric cancer [11]. However, MGC sometimes develops even after successful $H$. pylori eradication, with an annual incidence of $0.8-4.1 \%$ [9-15]. In most previous studies, only incidences of MGC within a 3-year median follow-up period were reported, and a study with a longer follow-up period is needed. Additionally, only a few studies have evaluated risk factors associated with the development of MGC [12, 13].

Our group previously reported that accumulation of aberrant DNA methylation induced by $H$. pylori infection and chronic inflammation in noncancerous gastric mucosae causes field cancerization, and that the degree of the field is strongly associated with the risk of development of gastric cancer [1622]. To demonstrate the usefulness of assessing the degree of epigenetic field cancerization, we recently conducted a multicenter prospective cohort study with a median follow-up of 2.97 years, and demonstrated that the methylation level of $m i R-124 a-3$ was associated with an increased risk of developing MGC [23]. The cohort established in the study has a high value because of its size, the sufficiently long period of follow-up (a median of 4.5 years), and the high patient followup rate $(97.9 \% ; 809$ of 826 patients).

Here, we performed a retrospective analysis to investigate the incidence of and nonepigenetic risk factors for MGC after patients had undergone endoscopic resection for early gastric cancer with successful $H$. pylori eradication using the above-mentioned cohort.

\section{Patients and methods}

\section{Patients}

A total of 826 patients who underwent ESD for early gastric cancer between 1999 and 2010 in one of three hospitals (National Cancer Center Hospital, Tokyo University Hospital, and Wakayama Medical University Hospital) were enrolled between 2008 and 2010 in the multicenter prospective cohort study [23]. One hundred nineteen patients who tested negative for $\mathrm{H}$. pylori infection without previous eradication were excluded, as were 100 patients who had already achieved successful eradication before detection of their initial gastric cancer. Thirteen patients who were followed up for less than 1 year were also excluded. The remaining 594 patients $(470,86$, and 38 patients at National Cancer Center Hospital, Tokyo University Hospital, and Wakayama Medical University Hospital, respectively) who underwent ESD and successful H. pylori eradication were analyzed retrospectively in the present study (Fig. 1). Among them, 210 were patients who gastric cancer had been newly diagnosed and treated when they were enrolled, and 384 were postresection patients who had previously

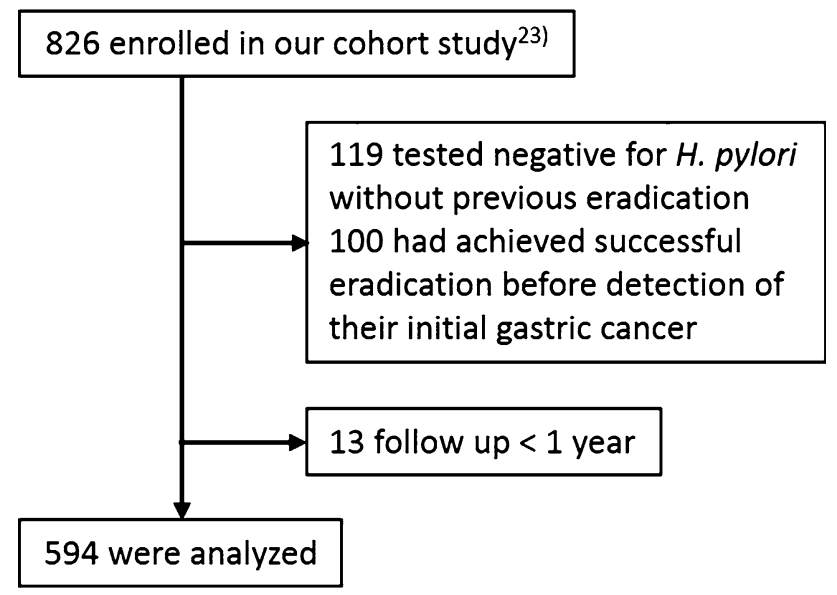

Fig. 1 Flowchart of study patients

undergone ESD and were in the follow-up phase. R0 resection was performed by ESD for all gastric cancer patients.

\section{Detection of Helicobacter pylori infection and its eradication}

The presence of $H$. pylori infection was examined with the urea breath test (Otsuka, Tokushima, Japan), serum anti- $H$. pylori antibody test (Eiken, Tokyo, Japan), and either the culture method or the rapid urease test (Otsuka, Tokushima, Japan). A positive result in at least one of these tests was considered evidence of $H$. pylori infection. To eradicate $H$. pylori, patients were treated with lansoprazole $(30 \mathrm{mg})$, amoxicillin $(750 \mathrm{mg})$, and clarithromycin $(200 \mathrm{mg})$, each taken twice daily for 1 week. Successful eradication was confirmed on a negative urea breath test 2 months or more after treatment. If eradication was unsuccessful, the patient received second-line eradication therapy. Implementation of third-line and further eradication therapy was at the discretion of the attending physician. To confirm continuous $\mathrm{H}$. pylori negative status, the urea breath test, serum anti- $H$. pylori antibody test, and the culture method were performed at 3 and 5 years after the patients' enrollment in the previous study [23]. If any of these follow-up examinations revealed positivity for $H$. pylori, additional eradication was performed.

\section{Evaluation of baseline gastric mucosal atrophy, the pepsinogen test, and lifestyle habits}

Baseline gastric mucosal atrophy immediately before successful $H$. pylori eradication was assessed endoscopically according to the Kimura-Takemoto classification [24], which correlates well with the histologic degree of atrophic gastritis. Gastric mucosal atrophy was divided into three categories: mild (closed type I and II), moderate (closed type III and open type I), and severe (open type II and III). Blood samples were collected on the day of the first endoscopy after 
the enrollment, and serum levels of pepsinogen (PG) I and PG II were measured by the LZ test (Eiken, Tokyo, Japan). Patients with a PG I level of $70 \mathrm{ng} / \mathrm{ml}$ or lower and a PG I/PG II ratio of 3 or less were considered positive for PG. A questionnaire-style survey on lifestyle habits (history of smoking, drinking, and green vegetable intake) was conducted for all patients when they were enrolled.

\section{Surveillance endoscopy and definition of metachronous gastric cancer}

Annual surveillance esophagogastroduodenoscopy was performed for all patients after endoscopic resection for initial gastric cancer. MGC was defined as a new gastric cancer detected at least 1 year after successful $H$. pylori eradication and located in an area other than the site of the previous endoscopic resection; this definition was in accordance with the previous study [23].

\section{Statistical analysis}

The cumulative incidence of MGC was calculated by Kaplan-Meier analysis. The follow-up period was calculated from the starting date of the latest successful H. pylori eradication to the date of detection of the initial MGC or the latest surveillance endoscopy. The person-year method was used to calculate the incidence of MGC, which included only initial MGCs; subsequent tumors were excluded if multiple MGCs developed.

We performed univariate analysis using the log-rank test to evaluate the relationship between the clinicopathological features and the probability of MGC development. We also performed multivariate using the Cox proportional hazards model for variables considered significant on univariate analysis in order to identify independent risk factors for MGC development. $P$ values less than 0.05 were considered to be statistically significant. All statistical analyses were performed by use of the statistical analysis software (SPSS, version 20; SPSS, Tokyo, Japan) and the statistical program R, version 3.1.1 (http://cran.r-project.org).

\section{Results}

\section{Patient characteristics and incidence of metachronous gastric cancer}

Table 1 shows the clinicopathological characteristics of participating patients. The cohort was mostly male (82\%: 485 of 594 patients), and the median follow-up period after successful $H$. pylori eradication was 4.5 years (range
Table 1 Patient characteristics

\begin{tabular}{|c|c|}
\hline \multicolumn{2}{|l|}{ Status at the time of enrollment } \\
\hline Newly diagnosed & $210(35 \%)$ \\
\hline Postresection follow-up & $384(65 \%)$ \\
\hline Age at the time of successful eradication (years) & $66(36-79)$ \\
\hline \multicolumn{2}{|l|}{ Sex } \\
\hline Female & $109(18 \%)$ \\
\hline Male & $485(82 \%)$ \\
\hline Follow-up period after successful eradication (years) & $\begin{array}{l}4.5 \\
(1.0-12.6\end{array}$ \\
\hline $\begin{array}{l}\text { Interval between detection of initial GC and successful } \\
\text { eradication (years) }\end{array}$ & $\begin{array}{l}1.3 \\
(0-16.0)\end{array}$ \\
\hline \multicolumn{2}{|l|}{ Baseline gastric mucosal atrophy } \\
\hline Mild & $14(2 \%)$ \\
\hline Moderate & $255(43 \%)$ \\
\hline Severe & $325(55 \%)$ \\
\hline \multicolumn{2}{|l|}{ Number of eradication treatments } \\
\hline 1 & $480(81 \%)$ \\
\hline$\geq 2$ & $114(19 \%)$ \\
\hline \multicolumn{2}{|l|}{ Location of initial GC } \\
\hline Upper third & $103(17 \%)$ \\
\hline Middle third & $267(45 \%)$ \\
\hline Lower third & $224(38 \%)$ \\
\hline Size of initial GC (mm) & $15(1-67)$ \\
\hline \multicolumn{2}{|l|}{ Histologic type of initial GC } \\
\hline Differentiated & $575(97 \%)$ \\
\hline Undifferentiated & $19(3 \%)$ \\
\hline \multicolumn{2}{|l|}{ Depth of initial GC } \\
\hline $\mathrm{T} 1 \mathrm{a}$ & $536(90 \%)$ \\
\hline $\mathrm{T} 1 \mathrm{~b}$ & $58(10 \%)$ \\
\hline
\end{tabular}

Number of GCs before successful Helicobacter pylori eradication Single $464(78 \%)$ Multiple $130(22 \%)$

Pepsinogen method Negative

Positive $354(60 \%)$

Smoking (pack-years)

0

$184(31 \%)$

1-39

$229(39 \%)$

$\geq 40$

$181(30 \%)$

Alcohol drinking

None/occasional

$367(62 \%)$

Almost daily

$227(38 \%)$

Green vegetable intake

Occasional

$398(67 \%)$

Almost daily

$196(33 \%)$

The data are expressed as the number or the median, with the percentage or range in parentheses

$G C$ gastric cancer 


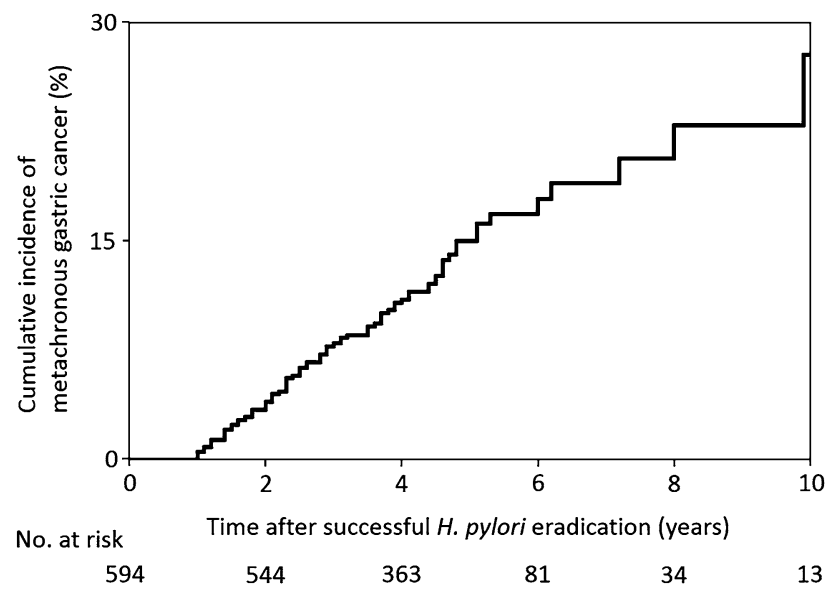

Fig. 2 Kaplan-Meier analysis for the cumulative incidence of metachronous gastric cancer after successful Helicobacter pylori eradication

1.0-12.6 years). Severe gastric mucosal atrophy was observed endoscopically in over half of the patients $(55 \%$ : 325 of 594 patients) just before successful eradication, and $22 \%$ of patients (130 of 594 patients) had multiple gastric cancers before successful eradication.

During the follow-up period, 94 MGCs were detected in 79 patients (13\%: 79 of 594 patients). Kaplan-Meier curves showed that the cumulative incidence of MGC 5 years after successful $H$. pylori eradication was $15.0 \%$ (Fig. 2). The incidence of MGC calculated by the person-year method was 29.9 cases per 1000 person-years (79 cases per 2645.1 person-years). The incidence of MGC when all subsequent MGCs were included was 33.4 lesions per 1000 person-pears (94 lesions per 2817.1 person-years).

\section{Risk factors for the development of metachronous gastric cancer}

Univariate analysis demonstrated that male sex, severe gastric mucosal atrophy, the location of the initial gastric cancer in the upper third of the stomach, multiple gastric cancers before successful $H$. pylori eradication, and smoking for 40 pack-years or more were significantly associated with the development of MGC (Table 2). Multivariate analysis for the risk of MGC revealed that male sex, severe gastric mucosal atrophy, and multiple gastric cancers before successful $H$. pylori eradication were independent risk factors (Table 3). Figure 3 shows Kaplan-Meier analyses by sex, severity of gastric mucosal atrophy, and number of gastric cancers before successful $H$. pylori eradication.

\section{Clinicopathological characteristics of metachronous gastric cancers}

Table 4 shows the clinicopathological characteristics of 94 MGCs detected in 79 patients during the follow-up period.
Table 2 Univariate analysis for the risk of metachronous gastric cancer $(M G C)$ development

\begin{tabular}{|c|c|c|}
\hline & $\begin{array}{l}\text { Probability of MGC development } \\
5 \text { years after successful eradication }(\%)\end{array}$ & $P$ \\
\hline \multicolumn{3}{|c|}{ Status at the time of enrollment } \\
\hline Newly diagnosed & 15.3 & \\
\hline $\begin{array}{l}\text { Postresection } \\
\text { follow-up }\end{array}$ & 15.4 & 0.40 \\
\hline \multicolumn{3}{|c|}{ Age at the time of successful eradication (years) } \\
\hline$<50$ & 14.6 & \\
\hline $50-59$ & 15.4 & 0.69 \\
\hline $60-69$ & 11.8 & 0.89 \\
\hline$\geq 70$ & 20.1 & 0.58 \\
\hline \multicolumn{3}{|l|}{ Sex } \\
\hline Female & 2.8 & \\
\hline Male & 17.7 & 0.002 \\
\hline
\end{tabular}

Interval between detection of initial GC and successful eradication (years)

$\begin{array}{lll}<1 & 14.3 & \\ 1-5 & 15.1 & 0.72 \\ \geq 5 & 15.9 & 0.58\end{array}$

Baseline gastric mucosal atrophy

Mild/moderate $\quad 8.9$

Severe $\quad 20.5$

0.001

Number of eradication treatments

$1 \quad 15.1$

$\geq 2 \quad 13.4$

0.95

Location of initial GC

Middle/lower third $\quad 13.9$

Upper third $\quad 20.1$

0.033

Size of initial GC (mm)

$<15 \quad 15.1$

$\geq 15 \quad 15.0$

0.45

Histologic type of initial GC

Differentiated $\quad 15.2$

Undifferentiated $\quad 7.1$

Depth of initial GC

T1a $\quad 15.2$

T1b $\quad 13.1$

Number of GCs before successful Helicobacter pylori eradication

Single $\quad 12.8$

Multiple $\quad 22.8$

Pepsinogen method

Negative $\quad 14.0$

Positive $\quad 15.7$

Smoking (pack-years)

$0 \quad 9.6$

$1-39 \quad 14.2$

$\geq 40 \quad 21.6$

Alcohol drinking

None/occasional $\quad 14.1$

Almost daily $\quad 16.4$

Green vegetable intake

Occasional $\quad 14.4$

Almost daily $\quad 16.1$

0.001

0.43

$G C$ gastric cancer 
Multiple MGCs developed in $16 \%$ of patients (13 of 79 patients), and $11 \%$ (10 of 94) of the MGCs were detected more than 5 years after successful $H$. pylori eradication. MGCs were mostly intramucosal, differentiated-type tumors that were cured by ESD performed according to the Japanese gastric cancer treatment guidelines [25], with the exception of one differentiated-type tumor that was $4 \mathrm{~mm}$

Table 3 Multivariate analysis for the risk of metachronous gastric cancer development for five variables considered significant on univariate analysis

\begin{tabular}{|c|c|c|}
\hline & $\mathrm{HR}$ & $P$ \\
\hline \multicolumn{3}{|l|}{ Sex } \\
\hline Female & 1 & \\
\hline Male & $3.72(1.36-10.21)$ & 0.011 \\
\hline \multicolumn{3}{|c|}{ Baseline gastric mucosal atrophy } \\
\hline Mild/moderate & 1 & \\
\hline Severe & $1.92(1.18-3.11)$ & 0.009 \\
\hline \multicolumn{3}{|l|}{ Location of initial GC } \\
\hline Middle/lower third & 1 & \\
\hline Upper third & $1.65(0.98-2.77)$ & 0.06 \\
\hline \multicolumn{3}{|c|}{ Number of GCs before successful Helicobacter pylori eradication } \\
\hline Single & 1 & \\
\hline Multiple & $1.84(1.15-2.95)$ & 0.011 \\
\hline \multicolumn{3}{|l|}{ Smoking (pack-years) } \\
\hline 0 & 1 & \\
\hline $1-39$ & $0.95(0.51-1.75)$ & 0.86 \\
\hline$\geq 40$ & $1.45(0.80-2.66)$ & 0.22 \\
\hline
\end{tabular}

The $95 \%$ confidence interval is given in parentheses

$G C$ gastric cancer, $H R$ hazard ratio in size, of category T1b (submucosal invasion $80 \mu \mathrm{m}$ ), and had lymphatic involvement.

\section{Discussion}

Our investigation clearly demonstrated the incidence of and risk factors for MGC in patients who underwent endoscopic resection for early gastric cancer with successful $H$. pylori eradication using data derived from a large-scale, multicenter prospective cohort study [23]. Several studies have reported annual incidences of MGC after $H$. pylori eradication, ranging from 0.1 to $0.5 \%$ in healthy individuals or peptic ulcer patients [26-33], and from 0.8 to $4.1 \%$ in patients after endoscopic resection for early gastric cancer [9, 11-15]. Individuals after endoscopic resection had a higher risk of MGC compared with those who were healthy or had peptic ulcers. Most of these previous studies, however, reported the incidence of MGC during a median follow-up of 3 years. A multicenter prospective randomized study [11] from Japan showed that the incidence of MGC in 255 patients who underwent $H$. pylori eradication was 14.1 cases per 1000 person-years during a 3-year follow-up period. The incidence of MGC in our present study (29.9 cases per 1000 person-years) was higher than that of the previous study. This variation may be due to differences in patient characteristics, as our study included a higher percentage of male patients as well as patients with severe gastric mucosal atrophy than the previous study; these factors are independent risk factors for MGC. Hence, $H$. pylori eradication aimed at reducing the
Fig. 3 Kaplan-Meier analysis for the cumulative incidence of metachronous gastric cancer after successful Helicobacter pylori eradication by sex (a), severity of gastric mucosal atrophy (b), and number of gastric cancers before $H$. pylori eradication $(\mathbf{c})$

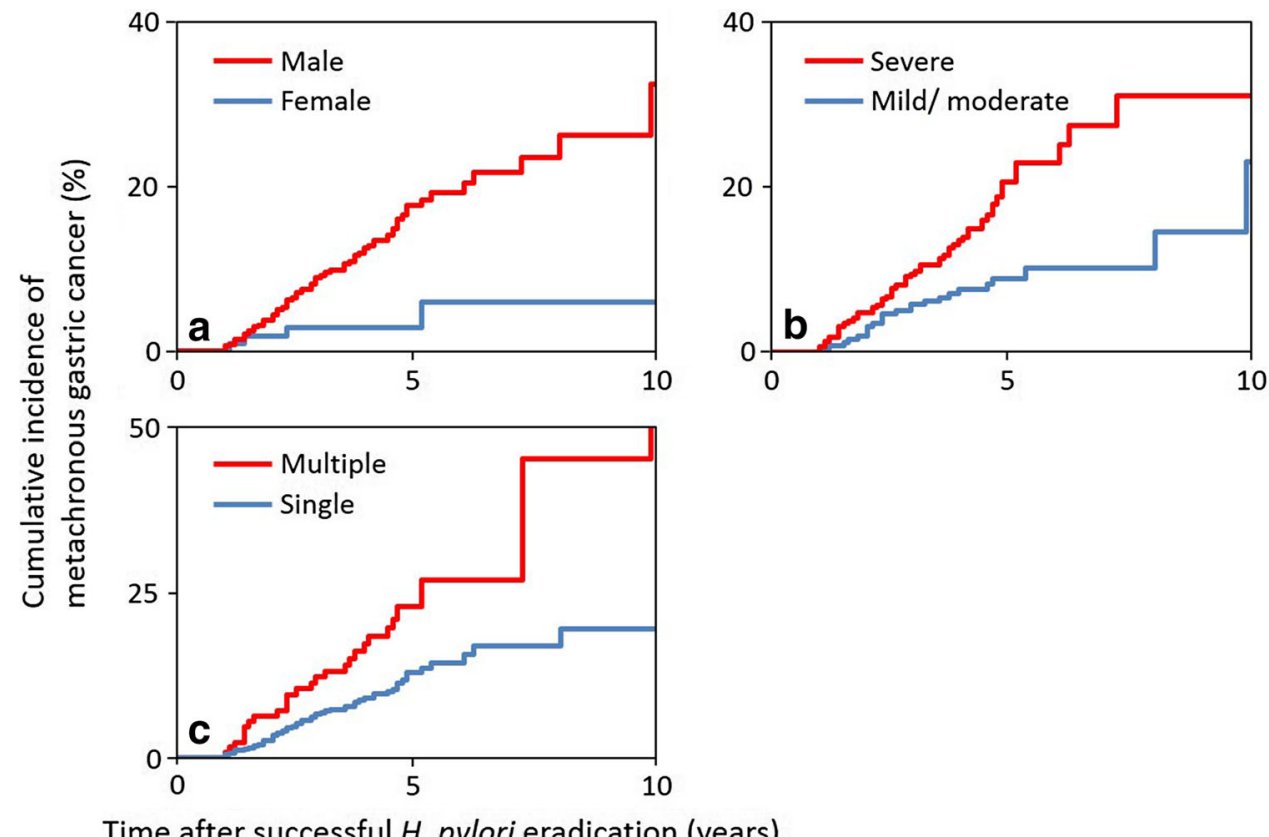

Time after successful $H$. pylori eradication (years) 
Table 4 Characteristics of 94 metachronous gastric cancers (MGCs) in 79 patients

\begin{tabular}{|c|c|}
\hline \multicolumn{2}{|c|}{ Number of MGCs per patient } \\
\hline 1 & $66(84 \%)$ \\
\hline 2 & $11(14 \%)$ \\
\hline 3 & $2(2 \%)$ \\
\hline \multicolumn{2}{|c|}{$\begin{array}{l}\text { Interval between successful Helicobacter pylori eradication and } \\
\text { detection of MGC (years) }\end{array}$} \\
\hline $1-3$ & $51(54 \%)$ \\
\hline $3-5$ & $33(35 \%)$ \\
\hline$\geq 5$ & $10(11 \%)$ \\
\hline \multicolumn{2}{|l|}{ Location } \\
\hline Upper third & $27(29 \%)$ \\
\hline Middle third & $36(38 \%)$ \\
\hline Lower third & $31(33 \%)$ \\
\hline Size $(\mathrm{mm})$ & $8(1-31)$ \\
\hline \multicolumn{2}{|l|}{ Macroscopic type } \\
\hline Elevated & $18(19 \%)$ \\
\hline Flat/depressed & $76(81 \%)$ \\
\hline \multicolumn{2}{|l|}{ Histologic type } \\
\hline Differentiated & $89(95 \%)$ \\
\hline Undifferentiated & $3(3 \%)$ \\
\hline Mixed & $2(2 \%)$ \\
\hline \multicolumn{2}{|l|}{ Depth } \\
\hline T1a & $90(96 \%)$ \\
\hline $\mathrm{T} 1 \mathrm{~b}$ & $4(4 \%)$ \\
\hline \multicolumn{2}{|c|}{ Lymphovascular involvement } \\
\hline Absent & $93(99 \%)$ \\
\hline Present & $1(1 \%)$ \\
\hline \multicolumn{2}{|l|}{ Ulceration } \\
\hline Absent & $91(97 \%)$ \\
\hline Present & $3(3 \%)$ \\
\hline \multicolumn{2}{|c|}{ Curability of endoscopic resection } \\
\hline Curative & $93(99 \%)$ \\
\hline Non curative & $1(1 \%)$ \\
\hline
\end{tabular}

The data are expressed as the number or the median, with the percentage or range in parentheses

risk of MGC development after endoscopic resection may have had a more limited effect in such patients. Similarly, a recent meta-analysis indicated that $H$. pylori eradication was less effective in preventing gastric cancer in patients with intestinal metaplasia [34]. Moreover, Kaplan-Meier analysis showed a linear increase in the cumulative incidence of MGC (Fig. 2); $11 \%$ of MGCs (10 of 94) were detected more than 5 years after successful $H$. pylori eradication (Table 4). Several cases of MGC detected more than 10 years after successful eradication of $H$. pylori were also reported $[35,36]$. It is therefore important to perform surveillance endoscopy continuously.

The present study clarified independent risk factors of MGC (including male sex, severe gastric mucosal atrophy, and multiple gastric cancers before successful $H$. pylori eradication) by multivariate analysis using the Cox proportional hazards model (Table 3). The sex difference in gastric cancer patients was clearly demonstrated in previous epidemiological studies [37]. Several studies have also reported that severe gastric mucosal atrophy was a risk factor for MGC development [12, 13, 29]. Our group has previously demonstrated that inflammation triggered by $H$. pylori induced aberrant DNA methylation in gastric mucosae; the accumulation of such methylation was strongly associated with a risk of gastric cancer development (epigenetic field cancerization) [17-23]. It is estimated that patients with severe gastric mucosal atrophy have high methylation levels because of long-term $H$. pylori infection and chronic inflammation. Additionally, we reported that patients with multiple gastric cancers had significantly higher methylation levels than those with a single gastric cancer [38]. These data indicate that severe gastric mucosal atrophy and multiple gastric cancers before successful H. pylori eradication are risk factors for MGC.

To the best of our knowledge, this study includes the largest number of subjects in published studies demonstrating MGC after endoscopic resection with $H$. pylori eradication. Moreover, strictly observed $H$. pylori infection by repeatedly using three examination methods in combination during the follow-up period.

The limitations of the current study include a heterogeneous patient population: both patients with newly diagnosed gastric cancer and postresection follow-up patients were enrolled. Therefore, individual patients had differing lengths of the interval between detection of the initial gastric cancer and successful $H$. pylori eradication. However, univariate analysis showed that any relationship between these differing lengths of the intervals and the probability of MGC development was not statistically significant (Table 2). A portion of our study patients who had already achieved successful H. pylori eradication before enrollment had the potential to show a decreased PG value because it was measured at the time of enrollment. It was impossible to evaluate the efficacy of the PG method precisely, although several studies have reported that $\mathrm{PG}$ is a predictive factor for gastric cancer development [12, 3941].

In conclusion, annual and continuous surveillance endoscopy for MGC in patients who have undergone endoscopic resection for early gastric cancer should be performed even after successful $H$. pylori eradication. This is particularly true for male patients, those with extensive gastric mucosal atrophy, and those who developed multiple gastric cancers before $H$. pylori eradication.

Acknowledgments The authors are grateful to Shigetaka Yoshinaga and Haruhisa Suzuki for patient enrollment and follow-up, and to 
Eiken Chemical for measuring serum pepsinogen and serum antiHelicobacter pylori antibody levels of all patients.

\section{Compliance with ethical standards}

Funding This study was supported by a Grant-in-Aid for Pioneering Basic Research from the Ministry of Health, Labour, and Welfare; and by the National Cancer Center Research and Development Fund, Japan.

Human rights statement and informed consent All procedures followed were in accordance with the ethical standards of the responsible committee on human experimentation (institutional and national) and with the Helsinki Declaration of 1964 and later versions. Informed consent or substitute for it was obtained from all patients for their being included in the study.

Conflict of interest The authors declare that they have no conflict of interest.

\section{References}

1. Isomoto H, Shikuwa S, Yamaguchi N, Fukuda E, Ikeda K, Nishiyama H, et al. Endoscopic submucosal dissection for early gastric cancer: a large-scale feasibility study. Gut. 2009:58:331-6.

2. Goto O, Fujishiro M, Kodashima S, Ono S, Omata M. Outcomes of endoscopic submucosal dissection for early gastric cancer with special reference to validation for curability criteria. Endoscopy. 2009;41:118-22.

3. Gotoda T, Iwasaki M, Kusano C, Seewald S, Oda I. Endoscopic resection of early gastric cancer treated by guideline and expanded National Cancer Centre criteria. $\mathrm{Br}$ J Surg. 2010;97:868-71.

4. Abe S, Oda I, Suzuki H, Nonaka S, Yoshinaga S, Odagaki T, et al. Short- and long-term outcomes of endoscopic submucosal dissection for undifferentiated early gastric cancer. Endoscopy. 2013;45:703-7.

5. Oda I, Oyama T, Abe S, Ohnita K, Kosaka T, Hirasawa K, et al. Preliminary results of multicenter questionnaire study on longterm outcomes of curative endoscopic submucosal dissection for early gastric cancer. Dig Endosc. 2014;26:214-9.

6. Ohnita K, Isomoto H, Shikuwa S, Yajima H, Minami H, Matsushima $\mathrm{K}$, et al. Early and long-term outcomes of endoscopic submucosal dissection for early gastric cancer in a large patient series. Exp Ther Med. 2014;7:594-8.

7. Suzuki H, Oda I, Abe S, Sekiguchi M, Mori G, Nonaka S, et al. High rate of 5-year survival among patients with early gastric cancer undergoing curative endoscopic submucosal dissection. Gastric Cancer. 2015. doi:10.1007/s10120-015-0469-0.

8. Nakajima T, Oda I, Gotoda T, Hamanaka H, Eguchi T, Yokoi C, et al. Metachronous gastric cancers after endoscopic resection: how effective is annual endoscopic surveillance? Gastric Cancer. 2006;9:93-8.

9. Kato M, Nishida T, Yamamoto K, Hayashi S, Kitamura S, Yabuta $\mathrm{T}$, et al. Scheduled endoscopic surveillance controls secondary cancer after curative endoscopic resection for early gastric cancer: a multicentre retrospective cohort study by Osaka University ESD Study Group. Gut. 2013;62:1425-32.

10. Shiotani A, Haruma K, Graham DY. Metachronous gastric cancer after successful Helicobacter pylori eradication. World J Gastroenterol. 2014;20:11552-9.

11. Fukase K, Kato M, Kikuchi S, Inoue K, Uemura N, Okamoto S, et al. Effect of eradication of Helicobacter pylori on incidence of metachronous gastric carcinoma after endoscopic resection of early gastric cancer: an open-label, randomised controlled trial. Lancet. 2008;372:392-7.

12. Shiotani A, Uedo N, Iishi H, Yoshiyuki Y, Ishii M, Manabe N, et al. Predictive factors for metachronous gastric cancer in highrisk patients after successful Helicobacter pylori eradication. Digestion. 2008;78:113-9.

13. Maehata Y, Nakamura S, Fujisawa K, Esaki M, Moriyama T, Asano K, et al. Long-term effect of Helicobacter pylori eradication on the development of metachronous gastric cancer after endoscopic resection of early gastric cancer. Gastrointest Endosc. 2012;75:39-46.

14. Choi J, Kim SG, Yoon H, Im JP, Kim JS, Kim WH, et al. Eradication of Helicobacter pylori after endoscopic resection of gastric tumors does not reduce incidence of metachronous gastric carcinoma. Clin Gastroenterol Hepatol. 2014;12:793-800.e1.

15. Bae SE, Jung HY, Kang J, Park YS, Baek S, Jung JH, et al. Effect of Helicobacter pylori eradication on metachronous recurrence after endoscopic resection of gastric neoplasm. Am J Gastroenterol. 2014;109:60-7.

16. Maekita T, Nakazawa K, Mihara M, Nakajima T, Yanaoka K, Iguchi $\mathrm{M}$, et al. High levels of aberrant DNA methylation in Helicobacter pylori-infected gastric mucosae and its possible association with gastric cancer risk. Clin Cancer Res. 2006;12:989-95.

17. Ushijima T. Epigenetic field for cancerization. J Biochem Mol Biol. 2007;40:142-50.

18. Nakajima $T$, Yamashita $S$, Maekita $T$, Niwa $T$, Nakazawa $K$, Ushijima $\mathrm{T}$. The presence of a methylation fingerprint of Helicobacter pylori infection in human gastric mucosae. Int $\mathrm{J}$ Cancer. 2009;124:905-10.

19. Niwa T, Tsukamoto T, Toyoda T, Mori A, Tanaka H, Maekita T, et al. Inflammatory processes triggered by Helicobacter pylori infection cause aberrant DNA methylation in gastric epithelial cells. Cancer Res. 2010;70:1430-40.

20. Nakajima T, Enomoto S, Yamashita S, Ando T, Nakanishi Y, Nakazawa K, et al. Persistence of a component of DNA methylation in gastric mucosae after Helicobacter pylori eradication. J Gastroenterol. 2010;45:37-44.

21. Nanjo S, Asada K, Yamashita S, Nakajima T, Nakazawa K, Maekita $\mathrm{T}$, et al. Identification of gastric cancer risk markers that are informative in individuals with past $H$. pylori infection. Gastric Cancer. 2012;15:382-8.

22. Ushijima T, Hattori N. Molecular pathways: involvement of Helicobacter pylori-triggered inflammation in the formation of an epigenetic field defect, and its usefulness as cancer risk and exposure markers. Clin Cancer Res. 2012;18:923-9.

23. Asada K, Nakajima T, Shimazu T, Yamamichi N, Maekita T, Yokoi $\mathrm{C}$, et al. Demonstration of the usefulness of epigenetic cancer risk prediction by a multicentre prospective cohort study. Gut. 2015;64:388-96.

24. Kimura K, Takemoto T. An endoscopic recognition of the atrophic border and its significance in chronic gastritis. Endoscopy. 1969;1:87-97.

25. Japanese Gastric Cancer Association. Japanese gastric cancer treatment guidelines 2010 (ver. 3). Gastric Cancer. 2011;14:113-23.

26. Correa P, Fontham ET, Bravo JC, Bravo LE, Ruiz B, Zarama G, et al. Chemoprevention of gastric dysplasia: randomized trial of antioxidant supplements and anti-helicobacter pylori therapy. J Natl Cancer Inst. 2000;92:1881-8.

27. Wong BC, Lam SK, Wong WM, Chen JS, Zheng TT, Feng RE, et al. Helicobacter pylori eradication to prevent gastric cancer in a high-risk region of China: a randomized controlled trial. JAMA. 2004;291:187-94. 
28. You WC, Brown LM, Zhang L, Li JY, Jin ML, Chang YS, et al. Randomized double-blind factorial trial of three treatments to reduce the prevalence of precancerous gastric lesions. J Natl Cancer Inst. 2006;98:974-83.

29. Take S, Mizuno M, Ishiki K, Nagahara Y, Yoshida T, Yokota K, et al. Baseline gastric mucosal atrophy is a risk factor associated with the development of gastric cancer after Helicobacter pylori eradication therapy in patients with peptic ulcer diseases. J Gastroenterol. 2007;42(Suppl 17):21-7.

30. Takenaka R, Okada H, Kato J, Makidono C, Hori S, Kawahara Y, et al. Helicobacter pylori eradication reduced the incidence of gastric cancer, especially of the intestinal type. Aliment Pharmacol Ther. 2007;25:805-12.

31. Ogura K, Hirata Y, Yanai A, Shibata W, Ohmae T, Mitsuno Y, et al. The effect of Helicobacter pylori eradication on reducing the incidence of gastric cancer. $J$ Clin Gastroenterol. 2008;42:279-83.

32. Yanaoka K, Oka M, Ohata H, Yoshimura N, Deguchi H, Mukoubayashi $\mathrm{C}$, et al. Eradication of Helicobacter pylori prevents cancer development in subjects with mild gastric atrophy identified by serum pepsinogen levels. Int $J$ Cancer. 2009;125:2697-703.

33. Mabe K, Takahashi M, Oizumi H, Tsukuma H, Shibata A, Fukase $\mathrm{K}$, et al. Does Helicobacter pylori eradication therapy for peptic ulcer prevent gastric cancer? World J Gastroenterol. 2009;15:4290-7.
34. Chen HN, Wang Z, Li X, Zhou ZG. Helicobacter pylori eradication cannot reduce the risk of gastric cancer in patients with intestinal metaplasia and dysplasia: evidence from a meta-analysis. Gastric Cancer. 2015. doi:10.1007/s10120-015-0462-7.

35. Take S, Mizuno M, Ishiki K, Yoshida T, Ohara N, Yokota K, et al. The long-term risk of gastric cancer after the successful eradication of Helicobacter pylori. J Gastroenterol. 2011;46:318-24.

36. Mitsunaga A, Tagata T, Hamano T, Teramoto H, Kan M, Mitsunaga $\mathrm{Y}$, et al. Metachronous early gastric cancer over a period of 13 years after eradication of Helicobacter pylori. Clin J Gastroenterol. 2014;7:490-5.

37. Fock KM. Review article: the epidemiology and prevention of gastric cancer. Aliment Pharmacol Ther. 2014;40:250-60.

38. Nakajima T, Maekita T, Oda I, Gotoda T, Yamamoto S, Umemura $\mathrm{S}$, et al. Higher methylation levels in gastric mucosae significantly correlate with higher risk of gastric cancers. Cancer Epidemiol Biomarkers Prev. 2006;15:2317-21.

39. Kato M, Asaka M. Recent development of gastric cancer prevention. Jpn J Clin Oncol. 2012;42:987-94.

40. Massarrat S, Stolte M. Development of gastric cancer and its prevention. Arch Iran Med. 2014;17:514-20.

41. Park SY, Lim SO, Ki HS, Jun CH, Park CH, Kim HS, et al. Low pepsinogen I level predicts multiple gastric epithelial neoplasias for endoscopic resection. Gut Liver. 2014;8:277-81. 